\title{
Estrategia audiovisual de comunicación política en la SelVa en Chiapas: la eXPERIENCIA DE los COMUnicadores tseltales Mariano Estrada y Arturo Pérez
}

\author{
Audio-visual Strategies of Political Communication in the Jungle Region of Chiapas: The Experience of the \\ Tseltal Activists Mariano Estrada and Arturo Pérez
}

\author{
Delmar Ulises Méndez-Gómez
}

Resumen: En México, la formación de comunicadores como comunitarios, que desarrollan su quehacer en las comunidades y se vinculan con los pueblos originarios a los que pertenecen, ha sido importante en las últimas décadas porque ha permitido la ampliación y circulación de la voz de quienes han sido invisibilizados y negados, así como el ejercicio de su derecho a la comunicación e información. En este texto se examina el trabajo audiovisual de los comunicadores tseltales Mariano Estrada y Arturo Pérez originarios de la región Selva de Chiapas, su proceso de formación, el sentido político de su trabajo y sus estrategias de comunicación.

Palabras clave: medios de comunicación, medios audiovisuales, cine documental, comunidades rurales.

Abstract: In Mexico, the training of local media professionals who refer to themselves as "grassroots communicators," and who work and develop their practices closely with their communities of origin, has been an important phenomenon in the past few decades. By exercising their right to express themselves, communicate, and obtain information, these grassroots communicators have enabled invisible and undervalued perspectives and voices to reach a broader audience. In this article, I analyze the audio-visual work of two Tseltal community media producers, Mariano Estrada and Arturo Pérez who share some of their professional experience and insights into the political dimension of "the camera," as well as their communication strategies and the work they have developed within Jungle Region communities.

Keywords: social media, audiovisual media, self-representation, documentary.

Delmar Ulises Méndez Gómez. Maestro en Comunicación y Política por la Universidad Autónoma Metropolitana. Investigador independiente. Temas de especialización: estudios visuales, sociología de la memoria y la violencia, cine de los pueblos originarios. Correo electrónico: delmarmego@gmail.com.
Enviado a dictamen: 23 de mayo de 2017.

Aprobación: 30 de octubre de 2017.

Revisiones: 2. 
E n este escrito se presentan algunos resultados de una investigación realizada sobre el trabajo comunitario y audiovisual desarrollado por Mariano Estrada y Arturo Pérez, comunicadores tseltales de la región Selva de Chiapas. El estudio de caso se inscribe en los lineamientos de la metodología cualitativa; se realizó investigación de campo y se aplicaron entrevistas considerando dos fuentes principales: los documentos audiovisuales y los testimonios de ambos comunicadores. En cuanto a los audiovisuales, se describió y analizó el contenido sonoro, narrativo y visual de los documentales realizados por ambos comunicadores a partir de los planteamientos de los estudios de la antropología visual (Zamorano, 2005 y 2009; Köhler, 2004) y de los estudios decoloniales (Schiwy, 2006; León, 2010). Además, se recuperaron algunas experiencias empíricas del uso del video en comunidades rurales llevadas a cabo por los autores citados.

Las fuentes audiovisuales se yuxtaponen con las testimoniales, lo cual permite comprender el sentido político que adquieren la cámara y el video, las formas de construir la narrativa y las estrategias de exhibición de los audiovisuales. Se estudió en especial la producción del documental titulado Viejo Velasco: la huella de la injusticia agraria (2007) para obtener un acercamiento al trabajo de Estrada y Pérez y a su forma de vincularse con la organización, con las comunidades y con los movimientos sociales. Es importante señalar que uno de los puntos que se encuentra en proceso de análisis es cómo las comunidades recibieron ${ }^{1}$ el documental propuesto, tema que por cuestiones de espacio no se aborda en este texto. Sin embargo, se considera que los testimonios de los comunicadores constituyen voces sociales que también dan cuenta de la reflexión de las comunidades sobre el documental, así como sobre elementos de disidencia y de interpelación hacia lo que en él se expresa; es decir, por medio del testimonio de los comunicadores se puede identificar el ámbito social en el que están insertos, así como: "los grupos sociales, las instituciones a las que están ligados, y que forman parte [... de la experiencia de vida de los sujetos" (Mallimaci y Giménez, 2006: 177). Las comunidades de la Selva por lo común no cuentan con la posibilidad de difundir sus problemáticas en los medios masivos de comunicación; éste es uno de los motivos por los cuales los comunicadores tomaron la cámara y la integraron como un medio de expresión para la colectividad y para compartir con el público distintas voces con el objetivo de dar cuenta de los problemas comunitarios.

\section{Las tecnologías audiovisuales en los pueblos originarios}

El uso de las tecnologías audiovisuales por parte de los pueblos originarios no es nuevo puesto que éstos se apropiaron de ellas y las integraron a las prácticas comunicativas de expresión, de acción y de interpelación desde principios de los años ochenta, a partir del impulso promovido por el Estado a través de diversos programas, así como por la academia, pero sobre todo por los movimientos sociales que se gestaron en diferentes momentos y a partir de distintas coyunturas sociales, políticas, culturales e históricas (Bartra y Otero, 2008). Las tecnologías audiovisuales: "han permitido un mayor acceso a medios como la fotografía, el cine, y principalmente el video, facilitando sus usos alternativos, populares y comunitarios" (Zamorano, 2005: 21).

Las primeras experiencias de video de los pueblos originarios de México se produjeron a principios de los años ochenta en algunas comunidades de Michoacán y Oaxaca, en donde integraron el video como un medio para mantener comunicación con los familiares que migraron a Estados Unidos y a otras partes del país, a partir de la realización de "videocartas" (Propios, 2004). Estas experiencias eran ajenas a los programas estatales, a diferencia del proyecto "Transferencia de Medios Audiovisuales a Comunidades y Organizaciones Indígenas" (TMA), implementado en 1989 a través del entonces Instituto Nacional Indigenista (INI) y asistido por algunos académicos y cineastas, ${ }^{2}$ con el cual inició la formación de los primeros videoastas en el manejo de tecnologías audiovisuales, que comprendía la grabación, la edición y la exhibición de sus propios videos (Ávila, 2014). 
Uno de los objetivos que sustentaron el proyecto TMA estaba dirigido a que los pueblos originarios y las organizaciones, por medio de sus videoastas, se construyeran visualmente, y pusieran su palabra y su mirada a favor de la lucha por el reconocimiento de una imagen propia a partir de lo que quisieran presentar y expresar (Becerril, 2015). Si bien una de las intenciones del proyecto TMA era proporcionar herramientas a los pueblos originarios para el desarrollo de sus propios medios de comunicación, no podían ocultarse los fundamentos indigenistas, integracionistas y asistencialistas del programa, por lo que, en respuesta a éstos, algunos de los videoastas formados en dicho proyecto decidieron encaminar sus propias organizaciones hacia el objetivo de formar comunicadores comunitarios de y para el pueblo, en un tiempo y contexto en el que diferentes comunidades buscaban espacios de enunciación para expresar sus demandas, rezagos, carencias y violencias de las que fueron, y todavía son, víctimas.

Uno de los casos más importantes es el de Ojo de Agua Comunicación A.C., organización oaxaqueña que desde su fundación en 1994 hasta la actualidad imparte talleres de video y radio en varios pueblos de Oaxaca y Chiapas. Destaca también la labor del comunicador chiapaneco Mariano Estrada Aguilar, quien se formó como realizador audiovisual en el proyecto TMA en 1992, y el trabajo de Arturo Pérez, este último formado en los talleres que Estrada impartió posteriormente en la Selva chiapaneca. Ambos comunicadores tseltales pertenecieron al área de comunicación de la organización Comité de Defensa por la Libertad Indígena-Xi'nich ${ }^{3}$ (CDLI-Xi'nich), con sede en el municipio de Palenque, que se fundó en 1986 con el objetivo de defender los derechos de los pueblos originarios de la región Selva de Chiapas. En su trabajo se centra el presente texto.

\section{Mariano Estrada y Arturo Pérez: su experiencia de formación audiovisual}

Mariano Estrada es un realizador audiovisual y comunicador tseltal originario de la comunidad
San Manuel, del municipio de Palenque, Chiapas. Interesado en las luchas de su comunidad, a los 15 años se integró en el Comité de Defensa por la Libertad Indígena-Xi'nich, lo que le permitió asistir a un taller de formación audiovisual organizado por el INI en el marco del proyecto TMA ya mencionado, en su tercera promoción ${ }^{4}$ realizada en 1992 . Tras recibir ese taller, en 1993 fundó el área de comunicación de la organización Xi'nich. Por su responsabilidad comunitaria, Estrada ha realizado su trabajo como comunicador de una manera constante durante más de veinticinco años, tanto dentro como fuera de la organización. De 1993 a 2014 realizó más de cincuenta videos, entre los que figuran cortos y mediometrajes documentales y cápsulas informativas.

Como parte de su compromiso social, Estrada realizó varios talleres sobre manejo audiovisual para las comunidades e integrantes del CDLI-Xi'nich con el objetivo de formar comunicadores que tuvieran conocimientos sobre el manejo de tecnologías audiovisuales. En uno de esos talleres participó Arturo Pérez, originario de la comunidad autónoma Cuauhtémoc Cárdenas, en Palenque, quien se formó como realizador en el año 2000, y posteriormente, interesado en los audiovisuales "porque tenía la curiosidad de saber cómo se grababa y cómo se hacían los videos", ${ }^{5}$ asistió a los cursos de comunicación comunitaria organizados por Ojo de Agua Comunicación A.C. en Oaxaca, en donde afinó sus conocimientos en el manejo de la cámara y en lenguaje fílmico.

Estrada y Pérez fueron compañeros de trabajo durante siete años, tiempo en el que desarrollaron varios videos entre los que destacan: Vientos deesperanza (2000), La cumbre sagrada (2003), Rostro de la historia indígena (2004) y Viejo Velasco: la huella de la injusticia agraria (2007). En estos videos Arturo Pérez fue el responsable de la cámara, con la que destacó por su manera de situarse ante los hechos y registrarlos; su perspectiva no es sólo la del documentalista o director de fotografía que busca necesariamente una "estética visual", sino la de un actor que se inserta en los movimientos sociales, que socializa las miradas y que busca comunicar de manera clara las ideas que se exponen, de tal modo que el espectador pueda comprender lo que se dice, es decir, ejerce una 
ética comunicativa. Estrada y Pérez comparten que el video "es una herramienta que funciona para registrar todo lo que pasa en las comunidades, es una forma de mostrar que algo sí sucedió". ${ }^{6}$ A ambos la cámara les permite hacer visible algo que acontece en la realidad y que consideran importante registrar y difundir. Afirman que la forma de construir el relato audiovisual busca ser honesta y verídica para los pueblos, que carecen de medios de información efectivos y accesibles.

Los comunicadores desempeñan su labor como un servicio a la comunidad y trabajan de manera voluntaria y sin retribución económica, lo cual provoca que tengan que suspender su servicio por temporadas. Por este motivo, después de un tiempo Arturo Pérez tomó la decisión de concluir su quehacer como comunicador para trabajar en la milpa y obtener recursos económicos para su sostenimiento y el de su familia. Por su parte, Mariano Estrada se ha mantenido como comunicador a pesar de las dificultades. "[El trabajo audiovisual] lo hago por pasión, no porque he encontrado de ahí dinero para vivir, de hecho los trabajos de video que hago, los hago en mis tiempos libres [...] yo no busco un fin monetario para todo lo que se hace". Gracias a su constancia, Estrada ha participado en múltiples festivales de cine y en encuentros de comunicación indígena en México y en otros países de Latinoamérica. De hecho, por su amplia trayectoria y su responsabilidad comunitaria fue nombrado coordinador general de la Coordinadora Latinoamericana de Cine y Comunicación de los Pueblos Indígenas (CLACPI) ${ }^{8}$ para el periodo 2015-2017, cargo que ejerce, a la fecha de escribir este texto, con entusiasmo y compromiso.

\section{¡Eso es una cámara! El sentido del lok'tawal}

El video, en el sentido más estricto, es una tecnología audiovisual, un soporte de grabación y un formato de producción que se caracteriza por su bajo costo y fácil manipulación (Rincón, 2006); por sus características, los actores de cualquier sociedad — sea hegemónica o subalterna- se pueden apropiar de esta tecnología para registrar lo que acontece cotidianamente. Además, esta herramienta puede ocuparse para recabar datos de investigación o para narrar cualquier acontecimiento o hecho social de manera estructurada al integrar elementos del lenguaje cinematográfico. Además, como señala Rincón, "el video brinda la posibilidad de mirar donde normalmente no se mira" (2006: 215); asimismo, desvela las múltiples maneras de observar y de presentar la realidad, posibilita narrar al otro y narrarse a sí mismo, y permite interrogar sobre quién ve y quién narra a quién. El video puede, entonces, considerarse como materia significante puesto que, al materializar en imágenes la realidad que se encuentra frente a nosotros para narrarla audiovisualmente, permite construir sentidos y significaciones. El video se constituye como una posibilidad del sistema de lenguaje (Hall, 2010) y permite que: "cualquier sujeto pueda contar su cotidianidad y su memoria, contarse a partir de la experimentación del sí mismo" (Rincón, 2006: 211), es decir, ser el autor/actor de su propia obra, que se constituye en relato.

Varios académicos han realizado estudios sobre el video como un hecho tecnológico y como un medio para el registro de la realidad, reflexionando también sobre las implicaciones económicas, sociales, culturales e ideológicas del uso de las tecnologías y de la materialidad producida. Algunas de las conclusiones a las que han llegado presentan diferencias; por ejemplo, varios autores aseveran que los videos reproducen la experiencia y el modo de producción capitalista (Aronowitz, 1979; Weiner, 1997 en Schiwy, 2006), mientras otros afirman que por medio del video se expresa la "identidad" de quienes lo producen (Ginsburg et al., 2002 en Zamorano, 2009). Asimismo, otros estudiosos destacan la capacidad de agencia de los actores que usan el video no sólo como un hecho cultural, sino político, como es el caso de algunos comunicadores comunitarios de América Latina: "El uso de la video-tecnología por los comunicadores indígenas involucra más que un resurgimiento de lo cultural. Es un esfuerzo por establecer los cimientos para una discusión que podría permitir que la gente indígena pueda co-determinar el tipo de sociedad y de orden económico que ellos quieran tener" (Schiwy, 2006: 47-48). 
Sobre esta misma línea se ha planteado también que los videos producidos por los comunicadores indígenas "contribuyen a recrear historias sobre la realidad social para atraer la atención sobre lo que ellos consideren relevante, necesario, posible, imaginable o deseable" (Zamorano, 2009: 264). Se reconoce que en los audiovisuales producidos por estos actores sociales hay una intención de hablar sobre problemáticas que se viven en las comunidades y que fuera de ellas difícilmente lograrán ser escuchadas; manifiestan el deseo de "intervenir en la realidad" mediante la construcción o transformación de una realidad política específica (Zamorano, 2009).

Los casos compartidos por Zamorano $(2005,2009)$ y Schiwy $(2003,2006)$ tienen correspondencia con la experiencia audiovisual y comunicativa de Estrada y Pérez, quienes tomaron la cámara de video para "aportar a la lucha". En los pueblos tseltales de Chiapas la cámara recibe el nombre de lok'tawal, palabra que puede traducirse al español como "con lo que se retrata o dibuja”; el lok'tawal es la cámara y también el resultado de una grabación. Asimismo, el documentalista es llamado lok'tawanej, palabra que traducida al español significa: "la persona que retrata", por lo que se puede interpretar que un lok'tawanej es aquel que registra con un video o fotografía la realidad mediante una cámara.

En palabras de un campesino de Chiapas, la cámara ha sido considerada como "un nuevo machete", es decir, como una herramienta de trabajo "porque se puede utilizar como un arma para defenderse o como instrumento de construcción o creación" (Köhler, 2004: 397). La metáfora del video como "un nuevo machete" también es compartida por Mariano Estrada, quien refiere de esta manera su encuentro con el video en el primer taller de formación audiovisual al que asistió en 1992:

Cuando llegamos al taller y vimos una cámara [...] La experiencia para mí fue algo fuerte porque no tenía conocimiento de lo que se puede producir por medio de una cámara. Yo no sabía qué era una cámara, mucho menos de video. Eso fue maravilloso porque empiezas a conocer otras cosas que hay y que pueden servirte.
En el proceso del taller fuimos descubriendo que puedes armar una historia [...y] transmitir esa historia con el audiovisual. ${ }^{9}$

El descubrimiento de la cámara de video fue crucial para Estrada y, por ello, al término del taller formó el área de comunicación de la organización CDLI-Xi'nich, en la cual integró el video al quehacer comunicativo: "para grabar los movimientos sociales, registrar las mesas de diálogo con las autoridades del gobierno estatal y federal, y evidenciar las amenazas, desplazamientos forzados, asesinatos y desapariciones". ${ }^{10}$ De esta manera, utilizó el video como herramienta política para acompañar la lucha de las comunidades de la Selva, y también fomentó el ejercicio de la comunicación y de la información para dichas comunidades, históricamente apartadas del mundo mediático.

La cámara de video para Estrada es un dispositivo tecnológico con el que se materializan los relatos de las comunidades, las cuales a través de ella expresan sus reflexiones y preocupaciones sobre temas como la migración, la pobreza, la salud, el despojo de la tierra, el uso de los agroquímicos o la pérdida de los conocimientos locales. Además, el video ha fungido como un medio de enunciación para reivindicar y compartir el valor de los ritos, las costumbres, las fiestas, el trabajo, las formas de ejercer la participación comunitaria, las autonomías y el reconocimiento de los derechos de la mujer en las comunidades; es decir, es un instrumento para compartir los esfuerzos que realizan los pueblos y las organizaciones en la construcción de comunidades integradas y colaborativas. Puede encontrarse una similitud entre el trabajo político que desarrolla Estrada y las experiencias de video en comunidades indígenas en Colombia que refiere Mora, quien concluye que: "el video indígena no se limita a la denuncia, ni siquiera a la resistencia. Va más allá, al comprometerse también con la representación de lo que es bueno para la vida" (2015: 44). Estrada remarca el lugar desde el que se posiciona, donde busca incidir con sensibilidad a través de los mensajes que expresa: "[E] video] no sólo lleva mensajes, sino también lleva alegría, emociones; entonces, podríamos hablar de mensajes que 
imprimen sensibilidad. No nos estamos estudiando a nosotros mismos, más bien estamos queriendo expresar nuestros sentimientos y dar a conocer nuestra situación a través de nuestros videos" (Estrada y Köhler, 2013: 97).

Una de las reflexiones de Estrada se refiere a la oposición entre la mirada/relato académica del antropólogo, del "otro" que ve y estudia, y la mirada/ relato del indígena, de ese "otro" que es "nosotros", que ve y vive en el propio cuerpo lo que estudia. En su reflexión se observa el distanciamiento objetivo/ subjetivo que quien maneja la cámara experimenta para construir el relato audiovisual. Estrada no remarca la distancia en términos de qué perspectiva es o no legítima, más bien señala que ambas son distintas o, como asevera Schiwy, "crea un circuito paralelo al de la producción intelectual, académica y [también mediática]" (2006: 58).

Yo siento que el realizador indígena plasma lo que siente y el antropólogo plasma lo que estudia, lo que ve, pero no lo que siente. Para el antropólogo es un proceso de aprendizaje, está estudiando. Y aquel otro que somos nosotros, no lo estamos estudiando, lo estamos viviendo (Estrada y Köhler, 2013: 97).

Estrada y Pérez no ejercen el distanciamiento "objetivo" que los académicos o intelectuales asumen para alcanzar una visión crítica de los acontecimientos, más bien mantienen un posicionamiento subjetivo crítico y autocrítico que se expresa al demostrar su sentido de pertenencia con la lucha y su compromiso militante que influye directamente en los temas que presentan y en cómo los presentan. El comunicador es, entonces, alguien que vive, siente y mira lo que acontece en la comunidad de la que forma parte y lo presenta de tal manera que las comunidades pueden apropiarse de los audiovisuales e integrarlos a su lucha, a la vez que a través de ellos pueden encontrar "eso que nos está haciendo distintos, lo que nos está lastimando". ${ }^{1}$

El video es un recurso para presentar los modos de mirar y pensar de las comunidades, para acercarse a sus realidades, para hacer visual lo visible y lo no visible; es un medio que permite la circulación de las demandas, las luchas y los logros de los pueblos. Cada uno de los problemas que se plantean preexiste al video, el cual se suma a los reclamos históricos como estrategia de comunicación política; por ello, los videos no pueden considerarse "como simples ejercicios de creación artística o de representación de la realidad, sino como verdaderas estrategias de agenciamiento político para la defensa de la vida y con un ideal de cambio en los paradigmas civilizatorios de nuestra sociedad" (Mora, 2015: 29). Esta búsqueda no depende únicamente de los comunicadores ni de los documentales por sí mismos, sino de los vínculos y de las redes de acción que se logran articular a partir de las reflexiones que las obras audiovisuales generan.

\section{La producción de los audiovisuales}

Durante los veinte años que Mariano Estrada dirigió el área de comunicación del CDLI-Xi'nich (1993-2013) enfrentó varios obstáculos debido a tres limitaciones principales: 1) los recursos económicos, 2) los recursos humanos y 3) los recursos técnicos. La primera limitación se debió a que la organización no aportaba fondos para la realización de los audiovisuales, es decir, para asumir los gastos de compra de equipo audiovisual y el pago de lo que se requería para el traslado de los comunicadores: alimentación, viáticos, hospedaje y pasajes. Estrada y Pérez afirmaron que realizaron la mayoría de los documentales con el dinero que cada uno aportó.

La segunda limitación se refiere a la falta de recursos humanos, que consiste en la dificultad para formar a nuevos comunicadores puesto que esta labor, a pesar del compromiso, la responsabilidad y el tiempo que exige, se hace sin percibir remuneración económica, lo que provoca que pocas personas se interesen en el quehacer audiovisual. Esta dificultad fue una de las razones por las que Arturo Pérez suspendió su labor comunicativa. "Tuve que dejar el trabajo de video porque tenía que irme a sembrar mi milpa, porque, si no, no me iba a alcanzar para comer; además tenía compromisos en mi comunidad que debía atender". ${ }^{12}$ Tanto Estrada como Pérez son campesinos que 
trabajan la tierra y de esa labor obtienen el dinero para los gastos de la familia, y en el caso de Estrada para continuar con su trabajo como comunicador. La falta de nuevos comunicadores ha provocado, por un lado, que Estrada se asuma como director, fotógrafo, guionista y editor de los documentales y, por el otro, que haya una discontinuidad en la producción audiovisual en los pueblos de la Selva en Chiapas.

La tercera limitación, la falta de recursos técnicos, está también vinculada con la falta de recursos económicos, que impide la adquisición de equipo audiovisual. Cuando Estrada fundó el área de comunicación de la CDLI-Xi'nich en 1993, recibió dos cámaras y dos computadoras para edición como parte del proyecto TMA, las cuales funcionaron durante diez años, pero después de ese tiempo Estrada se quedó sin equipo. La continuidad de su proyecto de comunicación fue posible porque recibió algunas donaciones, además de una beca de la Fundación Rockefeller que Estrada obtuvo por su trayectoria en 2007. Por vías de este tipo tanto Estrada como Pérez pudieron seguir con su labor; sin embargo, en más de una ocasión se vieron en la necesidad de solicitar equipo prestado a otros colectivos y organizaciones, específicamente a Koman Ilel, al Proyecto Videoastas Indígenas de la Frontera Sur y a Las Abejas de Acteal, con los que han creado redes de trabajo.

A pesar de las limitaciones, Estrada compartió que la principal razón por la cual no ha renunciado a ser comunicador es el respaldo que le brindan en las comunidades, donde le apoyan con donaciones de alimentos y con alojamiento cuando lo necesita, y por la disposición que manifiestan las personas al compartir sus testimonios frente a la cámara y al asistir a las exhibiciones. Estos gestos permiten pensar en otras dimensiones que se diferencian del cine comunitario que se desarrolla en Sudamérica, en países como Colombia, Brasil y Bolivia, en donde la comunidad se integra en todo el proceso de grabación, edición, difusión y exhibición de los documentales, y se decide mediante consenso los temas a producir. Por ello, puede pensarse que lo comunitario está relacionado no tanto con el nivel de involucramiento de las comunidades de la Selva en la producción audiovisual, sino con "el público que se identifica con las situaciones” (Zamorano, 2009: 268). Los videos son producidos por la voluntad personal de Mariano Estrada, pero con la intención de que éstos encuentren una correspondencia en los pueblos. Ésta es, a nuestro parecer, la característica de lo que llamamos "video en común", es decir, aquel que adquiere un sentido comunitario en tanto los videos logren ser reconocidos por las comunidades porque, aunque éstas no hayan participado en el proceso de realización, los temas tratados se vinculan con su devenir, sus experiencias y sus procesos culturales, sociales, políticos, económicos e históricos que: "resultan ser [...] los principales elementos que movilizan para dar autoridad y legitimidad a [la] producción audiovisual" (Zamorano, 2009: 264). El "video en común" es aquel que la comunidad reconoce como suyo y que busca intervenir y crear vínculos con otros pueblos.

Esto no quiere decir que las comunidades se apropien de los documentales sin debate porque, aun cuando Estrada se considere parte de la colectividad y con sus videos busque mantener correlatos con la visión social de la comunidad, en el proceso de visualización los interlocutores han manifestado disidencias que, por supuesto, son parte del diálogo. No hay, pues, una lectura cerrada ni un público homogéneo. Por ello, los documentales pueden considerarse obras abiertas (Eco, 1962) en tanto movilizan diversas lecturas y lo presentado es susceptible de ser aceptado o rechazado. Sin embargo, se considera que los videos logran generar sentidos de pertenencia porque tratan sobre temas como los desplazamientos forzados, las desapariciones y las masacres, que se viven no sólo en las comunidades de la Selva de Chiapas, sino en todo México y en diversos países de Latinoamérica.

\section{Tratamiento narrativo, visual y sonoro de los documentales}

La mayoría de los documentales realizados por Mariano Estrada y Arturo Pérez fueron diseñados por ellos mismos sin que se estableciera un consenso previo con la organización ni con las comunidades; es decir, 
no se tomaron decisiones colectivas sobre los temas a plantear, más bien ambos comunicadores reflexionaron sobre las inquietudes y necesidades comunitarias más urgentes, y a partir de ellas escribieron los guiones, en los que abordaban aspectos culturales y políticos de la región, que pudieran ser útiles para que las comunidades los reflexionaran. Por ello, en sus videos no plantean casos de comunidades ni personas específicas, sino abordan problemáticas que involucran en general a los pueblos, es decir, acontecimientos que se sufren y viven en las comunidades y que son expresados por distintos personajes, voces y miradas. Estrada mencionó que su punto de partida fueron sus propias experiencias, pero que éstas coincidían con las de su pueblo de origen:

No soy un extraño en la comunidad, soy de la comunidad, vivo en la comunidad, yo sé que el interés de un grupo o la necesidad de un persona es la misma necesidad que padezco [...] por eso hago algo que me afecta a mí y a todos, con esto quiero decirte que todo lo que yo proponga, ellos lo ven como algo que es de ellos. ${ }^{13}$

Estrada y Pérez utilizan una metodología de trabajo que les permite acercarse a las personas para dialogar con ellas en el momento en que suceden los hechos que desean narrar, y en otras ocasiones realizan entrevistas de manera formal presentando a los entrevistados en un cuadro y en un espacio específicos. En la mayoría de los videos se observa que las entrevistas ocupan un lugar secundario, y que más bien destacan los testimonios de las personas relacionados con ciertos acontecimientos. Ésta es una de las características del tratamiento audiovisual y narrativo que distingue el trabajo de Estrada, quien emprende largas caminatas por las veredas, de comunidad en comunidad, capturando con su cámara los paisajes, visitando a las familias, conversando con ellas en el interior de sus casas o en los patios. Con su cámara enfoca los gestos y las manos de sus interlocutores y muestra el espacio donde conversan.

Una de las particularidades del trabajo de Estrada es que el relato audiovisual está acompañado por una variada música de fondo. En algunos videos, por ejemplo en La cumbre sagrada (2003), el comunicador inserta música prehispánica, tradicional y popular, con la intención de reivindicar la música como un elemento identitario de los pueblos indígenas prehispánicos y actuales. En dicho video la música de conchas de caracol, de flauta y de tambores armoniza las escenas sobre un ritual sagrado en el que hombres y mujeres mayas se reúnen para pedir paz y justicia a los seres ancestrales como lo hacían, en palabras de Estrada, "los primeros padres". La voz en off de Estrada ofrece un discurso político que busca resaltar los conocimientos ancestrales de los pueblos que los vinculan con el pasado, con la naturaleza y con los dioses, al mismo tiempo que se escucha la música de fondo y se visualiza el danzar de la gente, las velas, el incienso y la comida, elementos del ritual. Estrada hace una crítica a la presencia militar en las comunidades de la Selva, que comenzó en la década de los noventa y que provocó el desplazamiento de cientos de personas por el miedo que ocasionaba el ejército. En otros documentales, por ejemplo en Rostro de la historia indígena (2004), Estrada utiliza música new age que, a nuestro parecer, permite crear un ambiente dramático en las escenas que presenta sobre la protesta e irrupción en el espacio público de varios movimientos sociales encabezados por los pueblos originarios y organizaciones, relevantes en la historia reciente de México.

Otra de las particularidades de sus documentales es que en algunos participa el mismo Estrada como narrador principal, al integrar su perspectiva con voz en off. En términos de estrategia de comunicación audiovisual, la voz en off de Estrada adquiere diferentes sentidos: por un lado, en algunos momentos pone en desventaja a las otras voces que componen la narrativa, porque los testimonios de los personajes aparecen como complementarios y mengua la fuerza testimonial. Esto se visualiza en el documental Mujer indígena: la vida olvidada (2003), donde la voz de Estrada ofrece datos históricos y descriptivos - hace una crítica a la esclavitud, las injusticias y el abandono que los pueblos indígenas sufrieron durante siglos-, y en algunos momentos resalta en la narrativa su percepción y, adicionalmente, 
aparece frente a la cámara. En este sentido reproduce, de algún modo, el gesto que expresan aquellos actores externos que hablan por el otro, sin dar el tiempo ni el espacio suficientes para que quien aparece frente a la cámara sea el actor y "el protagonista colectivo del relato" (Schiwy, 2006: 40).

Asimismo, la voz en off muestra la existencia de dos lenguas que se dirigen simultáneamente a varios públicos (Villarroel, 2010); una es la lengua materna que hablan algunos de los personajes - tseltal, tsotsil o ch'ol- y, otra, la que Estrada dispone, el español, con la intención de que los documentales puedan ser entendidos en otras regiones de México y de Latinoamérica. Sin embargo, surgen dudas sobre si los documentales se comprendieron en las comunidades indígenas donde no se habla español. Mariano Estrada explica por qué utiliza este idioma, que se traduce en la necesidad de provocar un entendimiento entre los de "afuera" y los de "adentro".

El español, para bien o para mal, es la lengua que nos obligaron a hablar y que nos vemos obligados a hablar para que nos entiendan. Una mayoría de los pueblos lo entendemos, a diferencia de nuestra lengua materna que sólo en las comunidades se habla [...] por eso busco que haya un entendimiento con los de dentro y los de fuera. ${ }^{14}$

Por otra parte, la voz en off encuentra momentos sugestivos al dialogar con los personajes y al funcionar como mediadora entre los testimonios contrastantes de la gente campesina y de los políticos; no subsume las voces, las articula. Esta característica se halla en varios de los documentales como: Rostro de la historia indígena (2004), La muerte del sueño antiguo (2005) y Viejo Velasco: la huella de la injusticia agraria (2007). En ellos la voz de Estrada se inserta como la de un integrante de la comunidad que busca pronunciarse en contra de la impunidad, la injusticia y la muerte; su sentir se compagina con el de los hombres y mujeres que comparten el sufrimiento, el camino y las pugnas. Es un gesto político que encuentra correspondencia con otras experiencias de cine, como en ejemplos de Bolivia, en donde las voces que aparecen en la narrativa: "evocan antecedentes comunes de opresión, sufrimiento y lucha" (Zamorano, 2009: 264). En sus documentales, Estrada también recupera la postura de los políticos sobre problemas como el territorio, la seguridad o el trabajo, para contrastar sus versiones con las de personas de las comunidades. En la voz en off de Mariano Estrada se hallan matices y diferentes perspectivas; no obstante, la intención de pugnar y de movilizar afecciones se encuentra inmersa en su voz y en la de los personajes.

La mayoría de los documentales de Estrada y Pérez tienen la particularidad de que fueron grabados con cámara en mano, sin el uso de trípode; esto es un indicativo de que en sus videos no buscan una variedad de planos ni de movimientos. Prefieren los planos medios y generales, y no se enfocan tanto en los detalles, sino dan cuenta del fondo que acompaña a los actores. Estrada reflexiona sobre su proceso creativo y su estilo narrativo:

No imito el estilo de nadie, busco ser yo mismo, me gustan los cortes directos; no me gustan los efectos. Me gusta la música de fondo, mucha música. Hay veces que los videos son narrativos, un texto en voz en off, hay otros en que no hay narrador, sólo imágenes, sonidos. Son estilos que vas aplicando como se te ocurra, no hay una estructura que me identifique, que diga: "Mariano hace las cosas así". En cada producción dejas tu estilo, y quizá no, pero siempre ando experimentando. ${ }^{15}$

En algunas ocasiones Estrada y Pérez realizaron dos versiones de un mismo documental porque, en palabras de Estrada: "una versión es para la comunidad donde fue hecho, pues ellos quieren verse todo el día, pero para otras es exagerado ver tanto tiempo un material, entonces, sin quitar todo, dejas la parte esencial del material y sacas una versión corta, pública, la de todos". ${ }^{16}$ La segunda versión es la que se exhibe en los festivales, encuentros y reuniones en los que participan, sobre todo en contextos urbanos, donde el ritmo es distinto al de las comunidades rurales, como es distinta también la forma de ver cine. Es importante señalar que ninguna 
de las dos versiones de los documentales se pone a la venta, ${ }^{17}$ ello porque, según afirman Estrada y Pérez, no tienen la intención de lucrar en nombre de los pueblos, ni buscan abrir un mercado, ni desean comercializar los documentales. Generalmente se hacen pocas copias que se quedan en la organización, y otras son donadas a las comunidades y organizaciones con las que colaboran. Los comunicadores informan a las personas y comunidades que aparecen en los documentales que éstos no serán vendidos, pero sí solicitan el permiso para que puedan ser difundidos y exhibidos en otras regiones. Los materiales no son propiedad exclusiva de la organización Xi'nich ni de los cineastas, sino que pertenecen a las comunidades. Esta decisión forma parte de las estrategias políticas de comunicación, que están orientadas a la búsqueda de otras vías de difusión alejadas de la lógica mercantil.

\section{Memoria y exhibición comunitaria del video Viejo Velasco: la huella de la injusticia agraria}

El compromiso de los comunicadores con su labor es una cualidad que las comunidades reconocen y respaldan. Estrada y Pérez consideran que la confianza de la gente se gana con el trabajo honesto y responsable, actitud que les permite acceder a espacios y encuentros negados para quienes no sean del pueblo o no colaboren con él. Esto les ha dado la oportunidad de presentarse con las cámaras a eventos y manifestaciones sociales con seguridad, puesto que muchas veces éstas suelen intimidar y generar desconfianza y molestia en las personas.

Una de las experiencias más significativas que recuerdan ambos comunicadores se refiere al documental que trata sobre uno de los acontecimientos más violentos de la historia reciente de los pueblos originarios de la Selva en Chiapas: la masacre de la comunidad Viejo Velasco. Esta masacre fue el colofón de un conflicto agrario que comenzó a gestarse en los años setenta, ${ }^{18}$ a partir del cual más de veintiocho comunidades de la Selva fueron amenazadas y desalojadas en múltiples ocasiones por el Estado mexicano, acusadas de invadir territorios que no les pertenecían. Durante los años 2005 y 2006 se establecieron varias mesas de negociación entre las veintiocho comunidades agraviadas y el gobierno de Chiapas para regularizar las tierras que ocupaban. Dichas mesas fueron registradas y grabadas por Estrada y Pérez, quienes acudieron en calidad de invitados. Tras varios meses de presión y amenazas a las comunidades, en la madrugada del 13 de noviembre del año 2006, un grupo de personas armadas atacó la comunidad de Viejo Velasco y provocó la muerte de cuatro personas, la detención de un ejidatario, la desaparición de dos ancianos ${ }^{19}$ y el desplazamiento de veinte hombres, ocho mujeres, cinco niños y tres niñas (Centro de Derechos Humanos Fray Bartolomé de las Casas, 2016).

Según el sentir del personal del Centro de Derechos Humanos Fray Bartolomé de las Casas (2016), la masacre y el miedo fueron mecanismos de violencia ejercidos por el Estado para lograr el desplazamiento forzado de la comunidad Viejo Velasco y "garantizar la conservación de la Reserva de la Biósfera Nacional". En ese contexto, el video se insertó a la protesta; los comunicadores tomaron la iniciativa de intervenir y decidieron revisar el material grabado para evidenciar las causas que llevaron a tal hecho. Estrada afirma que la masacre no se produjo de manera gratuita, sino que había sido planeada: "el video Viejo Velasco habla de la masacre de una comunidad que fue preparada desde el gobierno del Estado; el Estado sabía cómo debía hacer para desalojar a esta comunidad, en otras palabras, el video mismo lo va explicando con el testimonio de las personas y mi voz". ${ }^{20}$ Durante el momento crítico de la masacre y el desplazamiento posterior de ésta y otras comunidades que se vieron afectadas, los realizadores decidieron no entrevistar a personas que compartieran su testimonio del ataque. Únicamente retomaron los relatos de las personas que se expresaron durante las mesas de diálogo para dar elementos que explicaran las razones de las agresiones. Asimismo, se contactaron con las personas cuyos testimonios se anexaron al filme para pedirles permiso para usar su voz y su imagen, el cual concedieron.

No obstante, Pérez logró grabar el testimonio de la señora Petrona Nuñes, sobreviviente de la masacre, que 
fue compartido en la casa de unas monjas en Palenque, lugar en el que se refugió durante una temporada. "La señora Petrona estuvo un mes aproximadamente en la casa de las monjas, y ya después no supimos para dónde la llevaron [...] no sé si aguantó todavía como un año, y después de que se fue de la casa de la hermana, murió; todo lo que vio, yo creo que de eso se murió". ${ }^{21} \mathrm{La}$ señora Petrona Nuñes ya no pudo ver el video. A partir de los testimonios de los que disponían, Estrada y Pérez comenzaron a coordinarse, a seleccionar el material y a editar el video, para lo cual se reunían cada sábado en las instalaciones del CDLI-Xi'nich. Aplicaron una de las ideas básicas de Estrada, que ejerce durante la edición de cualquiera de sus trabajos: "el mensaje debe ser claro para las personas a quienes se les va a presentar". ${ }^{22}$

Una vez que contaron con el material, ambos comunicadores pidieron asesoría a la organización Xi'nich para valorar si lo que mostraban en el video no ponía en riesgo la integridad de las familias desplazadas o, incluso, de los propios realizadores, puesto que en el video señalaban como responsables directos de la masacre a los representantes del gobierno que estuvieron en las mesas de diálogo, a quienes se acusaba de haber planeado el crimen. La reunión les permitió afinar el video y establecer un diálogo entre los realizadores, la organización y los personajes que aparecían en el audiovisual para decidir el corte final del documental. Ésta fue de las pocas veces que la producción de un material articuló la participación y decisión colectiva de varias personas.

El video documental se terminó de editar a finales de mayo de 2007, año en que se presentó por primera vez en las instalaciones de la organización CDLI-Xi'nich, en Palenque. Los comunicadores afirmaron que los videos exigen un tiempo largo de realización porque implican un proceso lento de reflexión y escritura: "Generalmente nuestras ideas empiezan desde años antes y se terminan haciendo tres, cuatro o cinco años después [...] nosotros trabajamos no por tiempo, sino por idea, se va escribiendo, como nuestro ritmo es así". 23 Sin embargo, en el documental de Viejo Velasco hicieron una excepción ya que produjeron el material rápidamente, puesto que consideraron la importancia de contar con un documento audiovisual que respaldara la demanda de las comunidades agraviadas.

El documental fue titulado Viejo Velasco: la huella de la injusticia agraria y en él aparecen los testimonios de varias personas que expresaban su preocupación ante la tentativa de ser desalojados de sus tierras; se muestran las mesas de diálogo, los representantes del gobierno que asistieron a éstas, la presencia de militares en las comunidades amenazadas, y archivos fotográficos que dan cuenta de lo que quedó después de la masacre en la comunidad. La voz en off de Estrada ofrece datos históricos y estadísticos que contextualizan los hechos, articulada con el testimonio de los ejidatarios afectados, de manera que el material se compone de voces colectivas.

Estrada y Pérez decidieron exhibir el documental durante los años 2007 y 2008, iniciativa que fue apoyada por la organización CDLI-Xi'nich, por lo que se proyectó en las asambleas mensuales realizadas en las comunidades. Estas presentaciones fueron fundamentales para informar sobre el sufrimiento de las comunidades derivado de los problemas agrarios. El documental cumplía así con uno de sus primeros objetivos: construir reflexión y diálogo con los pueblos a partir de lo visto y narrado. Pérez mencionó cómo se generaba el diálogo después de cada exhibición:

Si hoy en la noche hacemos la proyección, en la mañana, tempranito, en la asamblea sacamos el análisis de lo que se vio en el video, se piensa en lo que nos pasa, en lo que nos hace el gobierno, en nuestros derechos, se hace al siguiente día. A las comunidades les gusta el video porque ellos mismos lo piden, y ya convocan a su gente en su comunidad y ya lo presentan ellos, a veces nos invitan y llega toda la gente. ${ }^{24}$

Las asambleas fueron espacios en los que se analizó el documental, puesto que, en palabras de Zamorano: "El video crea, con los testimonios y opiniones de actores sociales participes [...], un espacio en común de debate, negociación y desacuerdo, para concebir futuros políticos distintos" (2009: 263). El objetivo de 
Estrada y Pérez no consistía sólo en analizar el material, sino en informar y buscar la manera de intervenir y de apoyar la lucha de las comunidades afectadas, sustentar y reafirmar lo dicho, y estar conscientes de los cambios que se deben de dar en las comunidades para su propio bienestar:

Una de las cosas que se disfruta mucho es que se ven allí, que yo soy el protagonista, yo me estoy viendo [...] la comunidad misma se ve, reconocen al tío, al hermano, a la mamá, y lo que está diciendo; ino, pues sí tiene razón! Como que reafirman todo, se siguen reafirmando en cada proyección, es una experiencia bonita llegar a las comunidades. ${ }^{25}$

Ambos comunicadores organizaron exhibiciones del video en diferentes comunidades de la región Selva, $y$ una de las dificultades que enfrentaron fue que muchas carecían de energía eléctrica, lo que complicaba la exhibición e incluso provocó que el equipo de proyección se averiara: "Lo que hacíamos Arturo y yo era ir de comunidad en comunidad cada fin de semana, cada quince días o cada mes [...] llevábamos una planta de energía y ipuug! Se quemó la planta y nuestro proyector [...] nos quedamos sin equipo, ni las comunidades tienen el equipo". ${ }^{26}$

A finales de 2008 el video dejó de presentarse en las asambleas y comunidades ante la falta de recursos económicos, que impidió el traslado de los comunicadores a los pueblos y la compra de equipo nuevo. Esto provocó que muchas de las comunidades afectadas y desplazadas tras la masacre no pudieran ver el video; de hecho, a más de diez años del ataque muchos de los sobrevivientes no han visto todavía el material. Sin embargo, a pesar de que el documental no ha circulado en las comunidades desde 2008, el contenido no pierde vigencia porque la masacre continúa en la impunidad, no ha habido justicia ni se han reparado los daños que sufrieron las familias. No obstante, el documental ha formado parte de la construcción de redes de trabajo con otras organizaciones como el Centro de Derechos Humanos Fray Bartolomé de las Casas, que atiende actualmente el caso de la comunidad Viejo Velasco.
Esta asociación incluso realizó un video en 2014 titulado Campaña Rostros del Despojo: Viejo Velasco, ${ }^{27}$ en el que los sobrevivientes del ataque comparten sus testimonios y memorias de lo acontecido.

Además de este video mencionado y del realizado por Estrada y Pérez, no existen otras experiencias que registren los casos de las comunidades violentadas en la Selva de Chiapas; por esta razón, el documental Viejo Velasco: la huella de la injusticia agraria fue integrado en la compilación de videos realizados por los pueblos originarios de Chiapas titulado Xch'ulel jlumaltik (2015) - proyecto consolidado por el esfuerzo de comunicadores comunitarios, documentalistas y organizaciones-, con el fin de difundir uno de los casos de violencia todavía sin resolver.

El video devela sólo una parte de la realidad porque es una selección de acontecimientos, testimonios y experiencias que deja en los márgenes otros elementos; en este sentido, supone una delimitación de la mirada. Sin embargo, consideramos que, más allá de que el video se produjera con el fin de evidenciar la masacre cometida y ser integrado en la búsqueda de justicia, éste adquiere otros sentidos que le confieren los comunicadores, las organizaciones y las comunidades. Éste es, a nuestro parecer, un objetivo importante de la producción audiovisual: recrear la historia y la memoria, además de tejer redes de acción y de intercambio para consolidar vínculos que permitan unir luchas para reivindicar demandas, temas en los que los pueblos trabajan normalmente de manera aislada. El video puede ser, entonces, un detonador para generar tramas, intercambiar experiencias y fortalecer el andar de los pueblos en lucha.

\section{A modo de conclusión}

A partir de lo reflexionado sobre el quehacer audiovisual de los comunicadores Mariano Estrada y Arturo Pérez pueden concluirse algunos puntos. El primero es que las tecnologías audiovisuales para la realización de documentales adquieren dimensiones expresivas, de acción e interpelación en la práctica de los comunicadores y de la organización CDLI-Xi'nich. 
El hecho de adoptar las tecnologías y el lenguaje audiovisual como posibilidades comunicativas es un acto político destinado a fomentar nuevos medios de enunciación que permitan a las comunidades hacer públicos acontecimientos invisibilizados por los medios hegemónicos de comunicación y por las instituciones del Estado. Los documentales evidencian la posición desde la cual hablan los comunicadores y la subjetividad política de los actores sociales que en ellos se expresan: "habilitan un lugar de enunciación para aquellos sujetos e historias que han sido silenciados" (León, 2010: 36-37).

Una segunda conclusión es que, aun cuando las comunidades no se hayan integrado al proceso de producción de los audiovisuales, los documentales movilizan afecciones y reflexiones colectivas sobre las situaciones que viven, sienten y sufren las comunidades, que las relacionan con sus propias vivencias, lo que hace posible la creación de vínculos y redes de acción con otros pueblos, gesto que caracterizamos como el "video en común", porque que los videos posibilitan generar sentidos de pertenencia.

Por lo anterior, el cine documental es considerado como una herramienta de lucha y de protesta para acompañar las manifestaciones sociales que emprenden los pueblos y las organizaciones. Asimismo, la cámara de video se integra como un elemento de protesta porque hace posible la visibilización y la documentación de los casos, y se significa también como un mecanismo de defensa y como un testigo ante lo que acontece durante los movimientos. Además, el documental puede ser considerado como un artefacto de memoria aun cuando la comunidad por la que se hizo el material no la haya visualizado - como sucedió con la comunidad de Viejo Velasco-, porque éste puede ser recuperado por otros pueblos que han experimentado casos similares de violencia.

Finalmente, puede establecerse que la producción de documentales demuestra, de acuerdo con Mora (2015: 43), la "presentación de la existencia de otras epistemologías", en tanto los comunicadores comparten las formas de vivir, sentir, pensar, actuar y luchar de las comunidades, lo que no sólo se traduce en términos de disputa o pugna, sino en términos políticos por reivindicar los conocimientos, las prácticas y las manifestaciones culturales que recuperan para movilizar afecciones en y con los pueblos, y que se relacionan con "la apertura de la enunciación de la visualidad otra, para la visualización de una enunciación otra" (León, 2010: 38).

\section{Notas}

${ }^{1}$ Parte de los objetivos del estudio es analizar los testimonios de las comunidades que visualizan los documentales realizados por Estrada y Pérez para dar cuenta de los efectos que éstos tienen en la vida social de los pueblos, y valorar la aceptación, negación o rechazo de lo expuesto en los relatos audiovisuales. Estamos de acuerdo con lo que plantea Verón (1993), puesto que el audiovisual por sí mismo no adquiere sentido, es decir, el sentido no se encuentra dentro de él, sino que es construido por quien produce el material y por quien reconoce el video. Ésta es la condición de la producción de semiosis.

${ }^{2}$ Los antropólogos y cineastas que participaron en el proyecto TMA fueron: Paul Leduc, Luis Lupone Alfonso Muñoz y Alberto Becerril.

3 El CDLI es una organización compuesta por comunidades tseltales, zoques y ch'oles, fundada en septiembre de 1986 para luchar por los servicios de agua, educación y salud, por el reconocimiento de sus derechos como pueblos originarios y por el respeto a la tierra y el territorio. Actualmente la organización está conformada por más de cincuenta comunidades de las regiones Selva y Norte de Chiapas.

${ }^{4}$ Mariano Estrada mencionó que en el taller al que asistió llegaron alrededor de cuarenta alumnos de veinte organizaciones de varios estados de México. Sus maestros fueron Cristian Castro, Javier Solórzano, Guillermo Monteforte y Carlos Cruz. El taller, de sesenta días, se realizó en Tlacolula de Matamoros, Oaxaca.

${ }^{5}$ Pérez, entrevista, 15 de enero de 2016.

${ }^{6}$ Pérez, entrevista, 15 de enero de 2016.

${ }^{7}$ Estrada, entrevista, 31 de agosto de 2015.

8 La Coordinadora Latinoamericana de Cine y Comunicación de los Pueblos Indígenas (CLACPI) se 
creó en 1985 en el marco de la celebración del I Festival Latinoamericano de Cine y Video de los Pueblos Indígenas, en la Ciudad de México. Está integrada por un amplio grupo de organizaciones que impulsan la comunicación comunitaria, especialmente la producción de video como herramienta de afirmación cultural y de transformación social en regiones indígenas de Abya Yala (América Latina). Para mayor información consultar la página: www.clacpi.org/pagina-ejemplo-2/historia/.

${ }^{9}$ Estrada, entrevista, 31 de agosto de 2015.

${ }^{10}$ Estrada, entrevista, 31 de agosto de 2015.

${ }^{11}$ Estrada, entrevista, 31 de agosto de 2015.

${ }^{12}$ Pérez, entrevista, 15 de enero de 2016.

${ }^{13}$ Estrada, entrevista, 31 de agosto de 2015.

${ }^{14}$ Estrada, entrevista, 31 de agosto de 2015.

${ }^{15}$ Estrada, entrevista, 31 de agosto de 2015.

${ }^{16}$ Estrada, entrevista, 31 de agosto de 2015.

${ }^{17}$ Cuando le solicité a Mariano Estrada una copia de sus documentales, no hubo un intercambio económico, sino más bien un intercambio de capital simbólico, puesto que Estrada viajó a la ciudad de Palenque para darme las copias que necesitaba y yo, por mi parte, lo apoyé con el costo de los pasajes que dispuso para trasladarse al lugar acordado.

${ }^{18}$ Uno de los problemas se debe al control de los bienes comunales por parte de un grupo de lacandones formado en el año 1971 por Luis Echeverría Álvarez, expresidente de México, quien otorgó a 66 hombres lacandones la cantidad de 614321 hectáreas, lo cual los volvía en los únicos dueños (Red por la Defensa de la Tierra y el Territorio, 2006). Este decreto ocasionó que más de 45 pueblos tseltales, tsotsiles, zoques y ch'oles que vivían en ese territorio no fueran regularizados, a pesar de las solicitudes dirigidas al gobierno. Pero éste no fue el único problema porque, a partir de la creación de la Reserva de la Biósfera Montes Azules en 1979, se inició la amenaza de una nueva reubicación para varias comunidades como: Nuevo Tila, Flor de Cacao, San Jacinto Lacanjá, Dr. Manuel Velasco Suárez, entre otras (Centro de Derechos Humanos Fray Bartolomé de las Casas, 2010).

${ }^{19}$ Los ancianos son Mariano Pérez Guzmán y Antonio Péñate López, desaparecidos durante el ataque en 2006. Hasta la fecha no se sabe de ellos.

${ }^{20}$ Estrada, entrevista, 31 de agosto de 2016.
${ }^{21}$ Pérez, entrevista, 16 de enero de 2016.

${ }^{22}$ Estrada, entrevista, 31 de agosto de 2015.

${ }^{23}$ Estrada, entrevista, 15 de enero de 2016.

${ }^{24}$ Pérez, entrevista, 15 de enero de 2016.

${ }^{25}$ Estrada, entrevista, 31 de agosto de 2015.

${ }^{26}$ Estrada y Pérez, entrevista, 15 de enero de 2016.

${ }^{27}$ Disponibleen:www.youtube.com/watch?v=nd6rVrvPIXg.

\section{Referencias}

Ávila Pietrasanta, Irma (2014). "México". En Alfonso Gumucio Dagrón (coord.), El cine comunitario en América Latina y el Caribe. Bogotá: Fundación Friedrich Ebert, pp. 371-430.

Bartra, Armando y Gerardo Otero (2008). "Movimientos indígenas campesinos en México: la lucha por la tierra, la autonomía y la democracia”. En Mayo Sam y Paris Yeros (coords.), Recuperando la tierra. El resurgimiento de movimientos sociales en África, Asia y América Latina. Buenos Aires: CLACSO, pp. 401-428.

Becerril Montekio, Alberto (2015). "El cine de los pueblos indígenas en el México de los ochentas”. En Revista Chilena de Antropología Visual, 25: 30-49.

Centro de Derechos Humanos Fray Bartolomé de las Casas, A.C. (2007). "Diego Arcos es liberado por el desistimiento de la acción penal del Ministerio Judicial del Estado de Chiapas". Boletín de prensa, 24. San Cristóbal de Las Casas: Autor.

Centro de Derechos Humanos Fray Bartolomé de las Casas, A.C. (2010). A 4 años de la masacre de Viejo Velasco. Boletín de prensa conjunto. San Cristóbal de Las Casas: Autor.

Centro de Derechos Humanos Fray Bartolomé de las Casas, A.C. (2016). "Diez años de impunidad de la masacre de Viejo Velasco". Boletín de prensa. San Cristóbal de Las Casas: Autor.

Eco, Umberto (1962). Obra abierta. Barcelona: Planeta Agostini.

Estrada, Mariano (director) (2003a). La cumbre sagrada [documental]. México: Comité de Defensa de la Libertad Indígena-Xi'nich

Estrada, Mariano (director) (2003b). Mujer indígena: la vida olvidada [documental]. México: Comité de Defensa de la Libertad Indígena-Xi'nich 
Estrada, Mariano (director) (2004). Rostro de la historia indígena [documental]. México: Comité de Defensa de la Libertad Indígena-Xi'nich

Estrada, Mariano (director) (2005). La muerte del sueño antiguo [documental]. México: Comité de Defensa de la Libertad Indígena-Xi'nich

Estrada, Mariano y Arturo Pérez (directores) (2007). ViejoVelasco:lahuelladela injusticiaagraria [documental]. México: Comité de Defensa de la Libertad IndígenaXi'nich

Estrada, Mariano y Axel Köhler (2013). "Desde y para los pueblos originarios: nuestra video-producción en Chiapas, México". En Revista Chilena de Antropología Visual, 21: 80-103.

Hall, Stuart (2010). Singarantías. Trayectorias y problemáticas en estudios culturales. Colombia: Universidad del Cauca.

Köhler, Axel (2004). "Nuestros antepasados no tenían cámaras: el video como machete y otros retos de la video-producción indígena en Chiapas, México". Revista Chilena de Antropología Visual, 4: 391-406.

León, Christian (2010). "Visualidad, medios y colonialidad. Hacía una crítica decolonial de los estudios visuales". En La Tronkal (coord). Desenganche, visualidades y sonoridades otras, Quito: La Tronkal, pp. 33-52.

Mallimaci, Fortunato y Verónica Giménez (2006). "Historia de vida y métodos biográficos". En Irene Vasilachis de Galdino (coord.), Estrategias deinvestigación cualitativa. Barcelona: Gedisa, pp. 175-212.

Mora, Pablo (ed.). 2015. Poéticas de la resistencia. Video indígena en Colombia. Bogotá: Cinemateca Distrital, Instituto Distrital de las Artes.

Propios Yusta, Cristina (2004). "Cine y video indígena: ¿hacia una comunicación alternativa?" En Elisenda Ardèvol y Nora Muntañola (coords.), Representación y cultura audiovisual en la sociedad contemporánea. España: Editorial UOC, pp. 316-338.

Red por la Defensa de la Tierra y el Territorio (2006). "Pronunciamiento de la Red de Defensa de la Tierra y el Territorio respecto a la masacre". Noticias de la Selva Lacandona. Disponible en: http://noticiasdelacandonia. blogspot.mx/2010/01/recordando-la-masacre-de-nuevovelasco.html. (consultado el 10 de enero de 2016).

Rincón, Omar (2006). Narrativas mediáticas. Barcelona: Gedisa.

Schiwy, Freya (2003). "Descolonizar las tecnologías del conocimiento: video y epistemología indígena”. En Catherine Walsh(ed.), Estudiosculturales Latinoamericanos. Retos desde y sobre la región andina. Ecuador: Universidad Andina Simón Bolivar, pp. 303-312.

Schiwy, Freya (2006). "Descolonizando el encuadre: video indígena en los Andes". En Walter Mignolo, Freya Schiwy y Nelson Maldonado-Torres (coords.), (Des)colonialidad del ser y del saber (videos indígenas y los límites coloniales de la izquierda) en Bolivia. Buenos Aires: Del Signo, pp. 31-6l.

Verón, Eliseo (1993). La semiosis social. Fragmentos de una teoría de la discursividad. Barcelona: Gedisa.

Villarroel, Mónica (2010). "El arte del video indígena en los Andes”. En Revista Chilena de Antropología Visual, 16: 76-94.

Zamorano Villarreal, Gabriela (2005). "Entre Didjazá y la Zandunga: iconografía y autorepresentación indígena de las mujeres del istmo de Tehuantepec, Oaxaca". En Liminar. Estudios Sociales y Humanísticos, III(2): 21-33.

Zamorano Villarreal, Gabriela (2009). "Intervenir en la realidad'. Usos políticos del video indígena en Bolivia”. En Revista Colombiana de Antropología, 45(2): 259-285. 
Foto 1. Mariano Estrada Aguilar, 2016

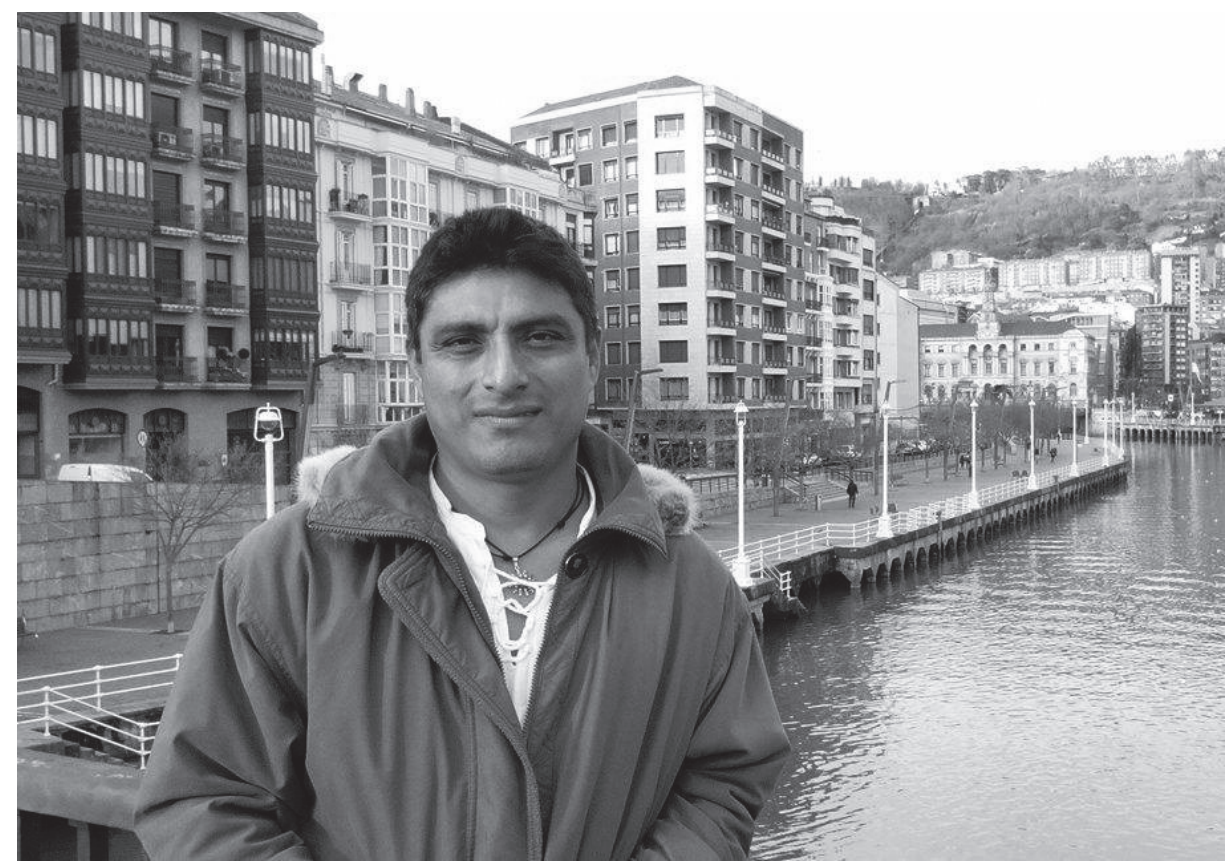

Fuente: Mariano Estrada. Cedida por el comunicador.

Foto 2. Testimonio de la señora Petrona Nuñes

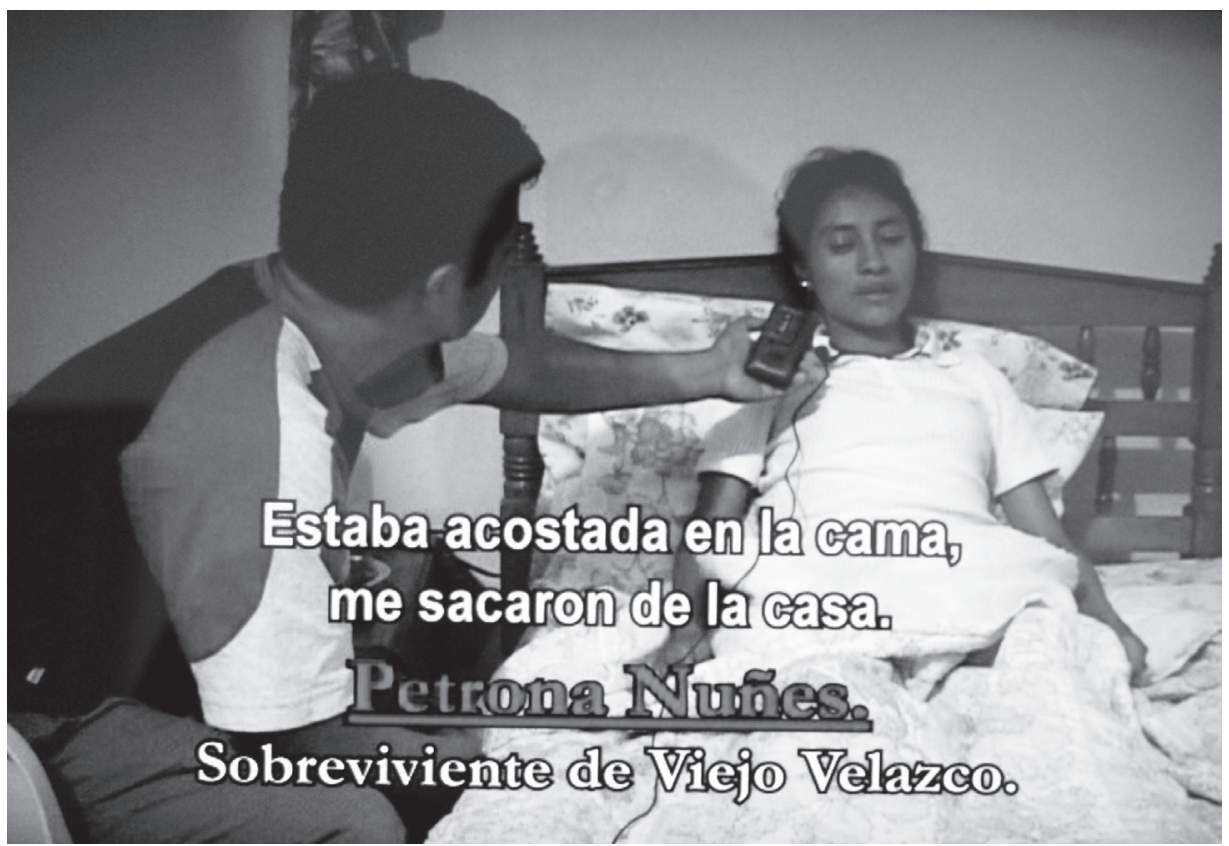

Fuente: Viejo Velasco: la huella de la injusticia agraria (2007). 
Foto 3. Testimonio de los afectados de Viejo Velasco

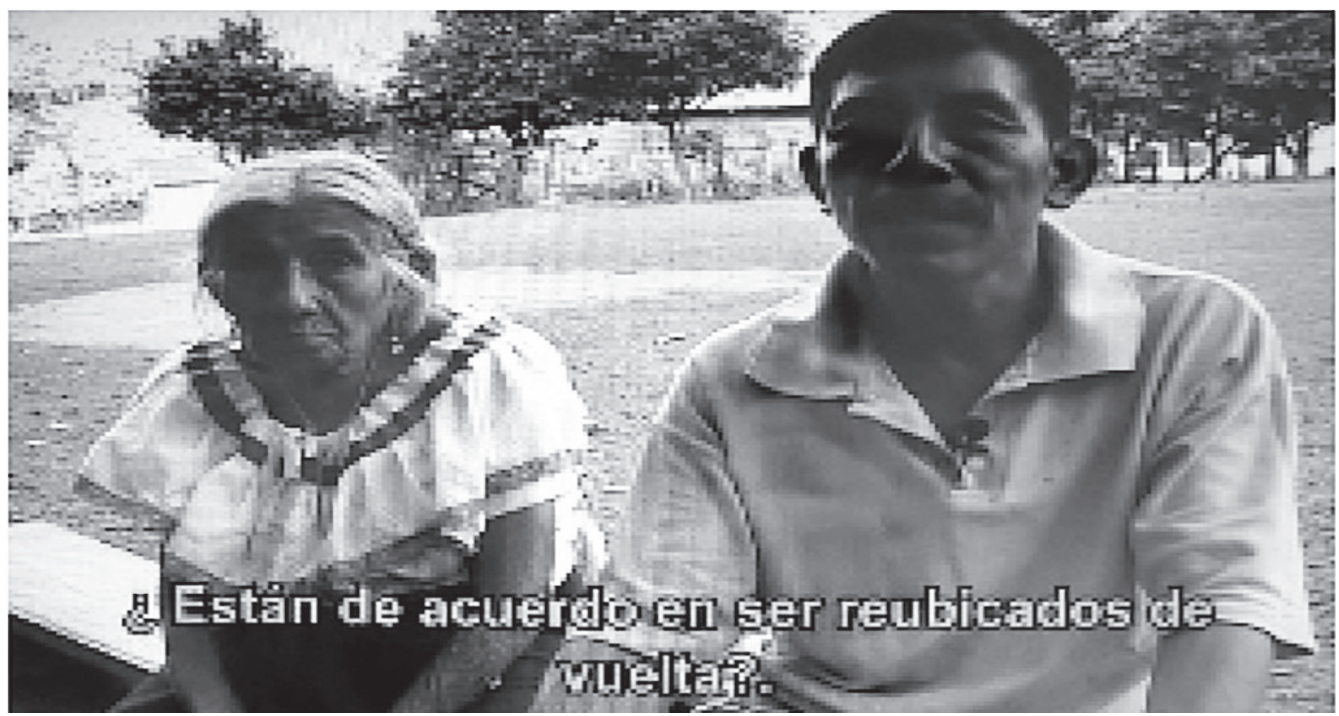

Fuente: Viejo Velasco: la huella de la injusticia Agraria (2007).

Foto 4. Mesas de negociación

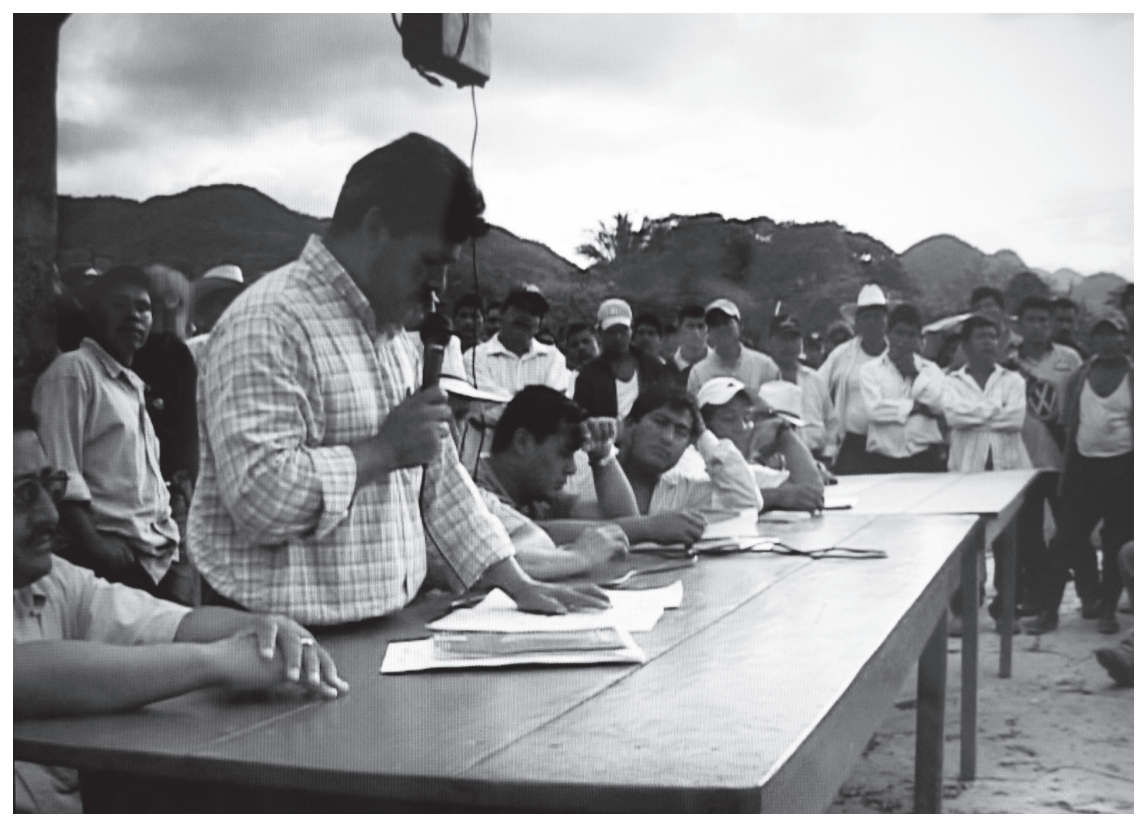

Fuente: Viejo Velasco: la huella de la injusticia Agraria (2007). 